\title{
A Small WWII Italian Bunker in Heraclea Minoa (Sicily)
}

\author{
Giancarlo T. Tomezzoli \\ European Patent Office, Munich, Germany \\ Email: gtomezzoli@epo.org
}

Received 3 July 2015; accepted 7 August 2015; published 10 August 2015

Copyright (C) 2015 by author and Scientific Research Publishing Inc.

This work is licensed under the Creative Commons Attribution International License (CC BY). http://creativecommons.org/licenses/by/4.0/

(c) (i) Open Access

\begin{abstract}
In this article, a WWII small Italian bunker evocative of the emotions caused to the Sicilian population by the WWII terminated 70 years ago was presented. It is a bunker of type T Monoarma (i.e. bunkers for a single weapon), indicated also as type Ispettorato, and located on the Sicilian seashore, near the archaeological site of the ancient Greek city of Heraclea Minoa.
\end{abstract}

\section{Keywords}

WWII, Sicily, Bunker, T Monoarma, Ispettorato, Heraclea Minoa

\section{Introduction}

Although terminated 70 years ago, the emotions caused by the WWII are still vivid in the last generations who survived those events and those emotions were unconsciously evocated in the Sicilian younger generations by abandoned Italian military structures that occasionally can be spotted here and there in the land and on the seashore. Particularly, evocative of said emotions is the vision of a small bunker located on the Sicilian sea shore, near the archaeological site of the ancient Greek city of Heraclea Minoa.

\section{Location of the Bunker}

The bunker, located high on the sea level, is not far from the ruins of the ancient Greek theatre of the city (cf. Figures 1-3) and is not indicated to the visitors. It was probably built in the period 1942-1943.

The WWII Italian bunkers are not precisely classified as the WWII German bunkers (Rolf, 1968), but of them exist various project plans produced by the Inspectorate of the Combat Support Units of the Italian Army in 1942. According to said project documentation, this small bunker belongs to the type T Monoarma bunkers (i.e. bunkers for a single weapon), indicated also as Ispettorato type bunkers (Grioni, 2013). Because sometime seen 


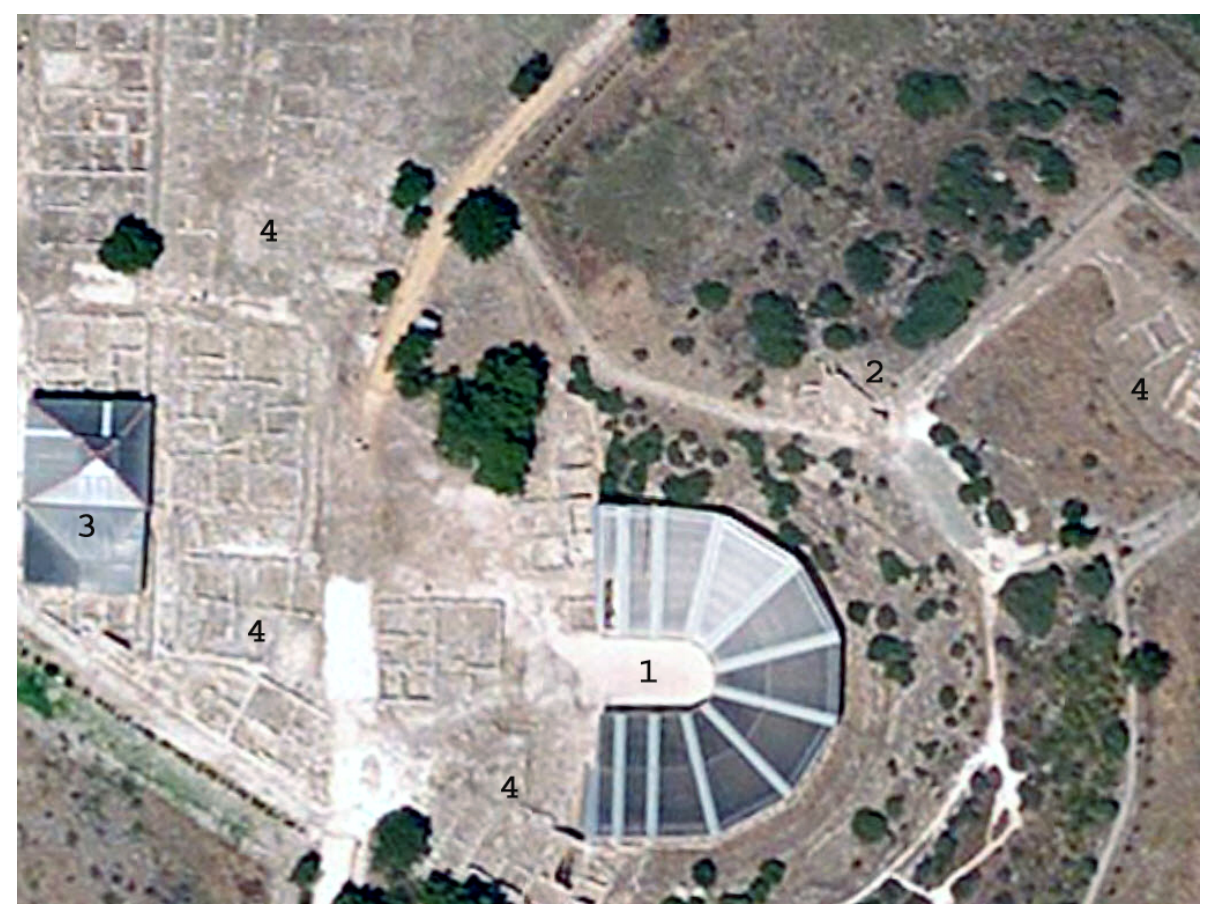

Figure 1. Location of the small bunker: 1, ruins of the Greek theatre; 2, bunker $\left(37^{\circ} 23^{\prime} 40.0^{\prime \prime} \mathrm{N}\right.$, 1316'48.9"E); 3, Archaeological Museum; 4, archaeological site of Heraclea Minoa-Flash Earth.

from above (cf. Figure 4), said type of bunker presents an outline resembling a keyhole, they are indicated also as keyhole bunkers. Certainly it was intended for the surveillance and the point defence of this part of the Sicilian coast and surely it was part of a more extended coastal defence system. However, no other bunker or defence structure, like for example trenches, have been discovered around it.

\section{Description of the Bunker}

In approaching the bunker, the attention is attracted by its low profile and the protruding inclined entrance portal (cf. Figure 2 and Figure 3) which protect the access stair, similar to the portals noticed in other Italian bunkers already described in previous articles (Collana SISM, 2014), (Tomezzoli, 2012). On the portal is located a tele-camera for the monitoring of the archaeological site.

The bunker, built in concrete, is approximately $12 \mathrm{~m}$ long, $4 \mathrm{~m}$ wide and the diameter of the circular gun chamber is about $4.5 \mathrm{~m}$. The interior of the bunker is not accessible; therefore, its internal structure has been only approximatively determined (cf. Figure 8 and Figure 9). An internal, rectangular chamber served as soldier shelter and the circular gun chamber allowed a $270^{\circ}$ defence of the outside of the bunker. The gun chamber is covered by a slight arched roof and its three menacing, rectangular embrasures are protected by four outgoing radial walls built with local stones (cf. Figure 5 and Figure 6, Figure 8 and Figure 9). The width of these walls is about $50 \mathrm{~cm}$ and the width of the walls of the gun chamber, estimated through the depth of the embrasures, is about $60-70 \mathrm{~cm}$. In the bunker could be lodged a group of four to six soldiers with an officer. But, it is possible that only one or a couple of soldiers was continuatively present in the bunker for monitoring the coast; the other soldiers were lodged in a nearby, disappeared barrack. Only in case of alarm, the complete group of soldiers ran to the bunker. The combat equipment consisted very probably of the personal weapons of the single soldiers: Carcano rifles Type 91/38 or Type 91/41 and machine pistols Beretta MAB 38, and of a machine gun Breda 37, mounted on a tripod positioned on a wooden platform, to be aligned, according to the combat exigencies, with one or the other of the three embrasures of the gun chamber. Because no traces of bitumen were found on the top of the bunker, it had no insulation against bad weather conditions. Because no chimney exists, it was not heated. Because the interior was narrow and not suitable for accommodating a kitchen, the meals were prepared elsewhere or on an open fire place. It is also possible that pre-cooked meals were brought to the soldiers from 


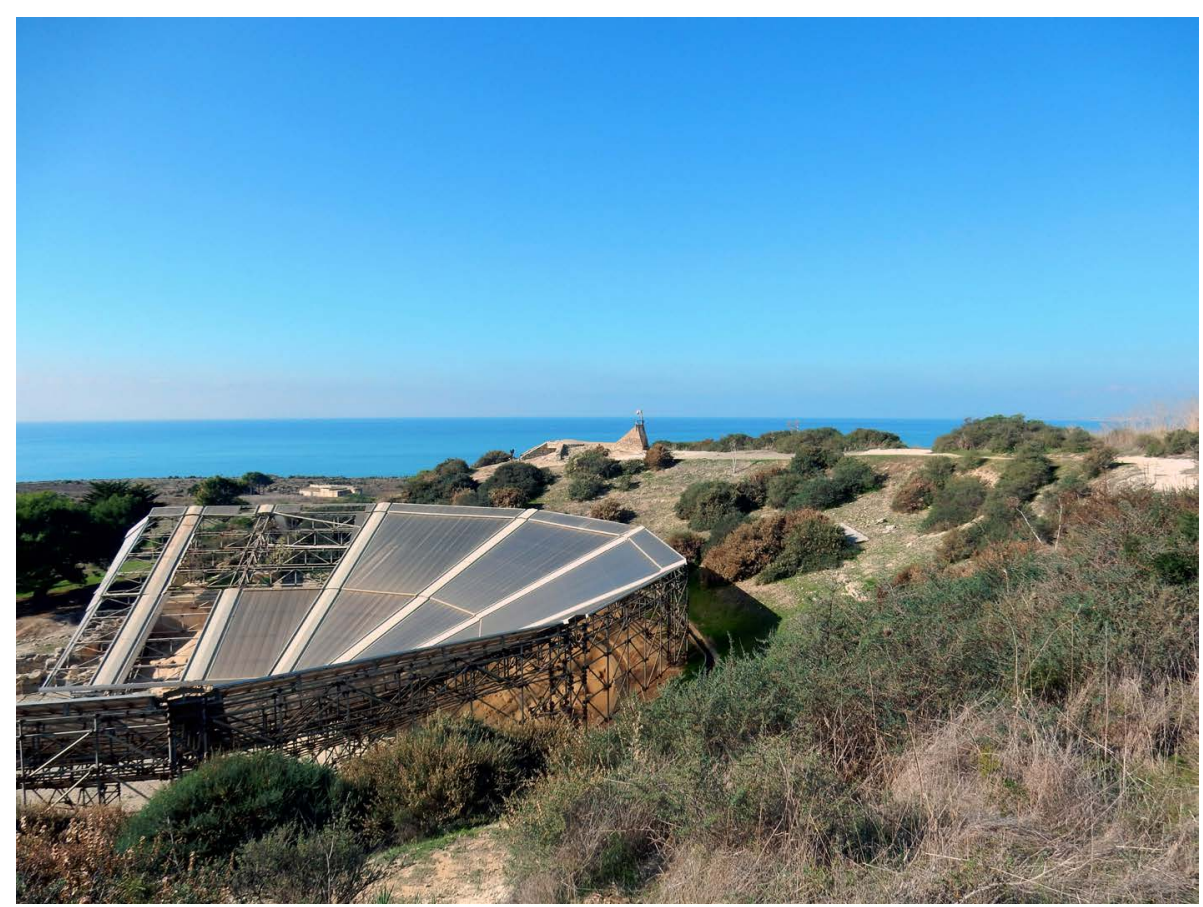

(a)

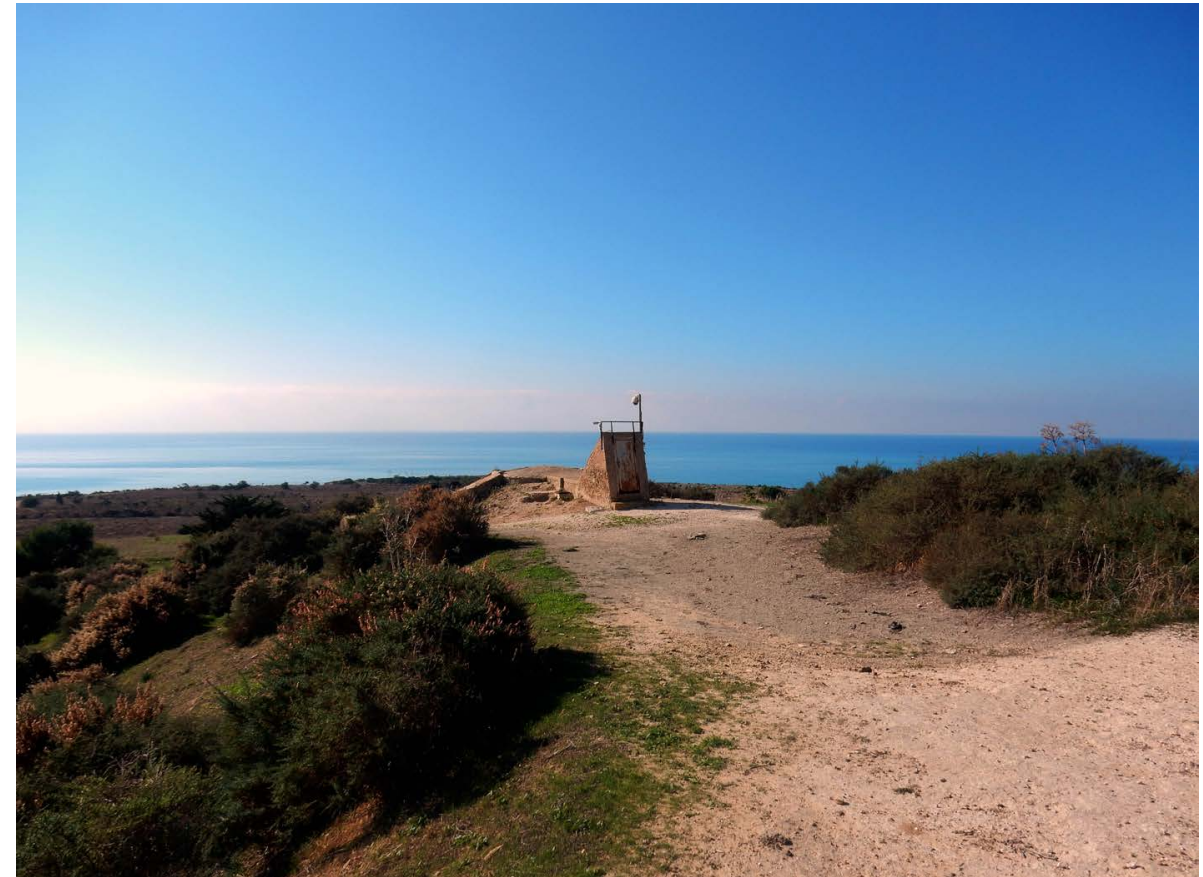

(b)

Figure 2. (a) In the middle, location of the small bunker in relation to the ancient Greek theatre and the Sicilian seashore of Heraclea Minoa; (b) The protruding inclined entrance portal of the bunker.

military or civilian kitchens not far away.

The view from the embrasures (see Figure 7) enabled to remark, that an internal wall separates the soldier shelter from the entrance stair. This internal wall is provided with a square embrasure, enabling the internal defence of the bunker; a similar wall with embrasure was noticed in other Italian bunkers described in previous 


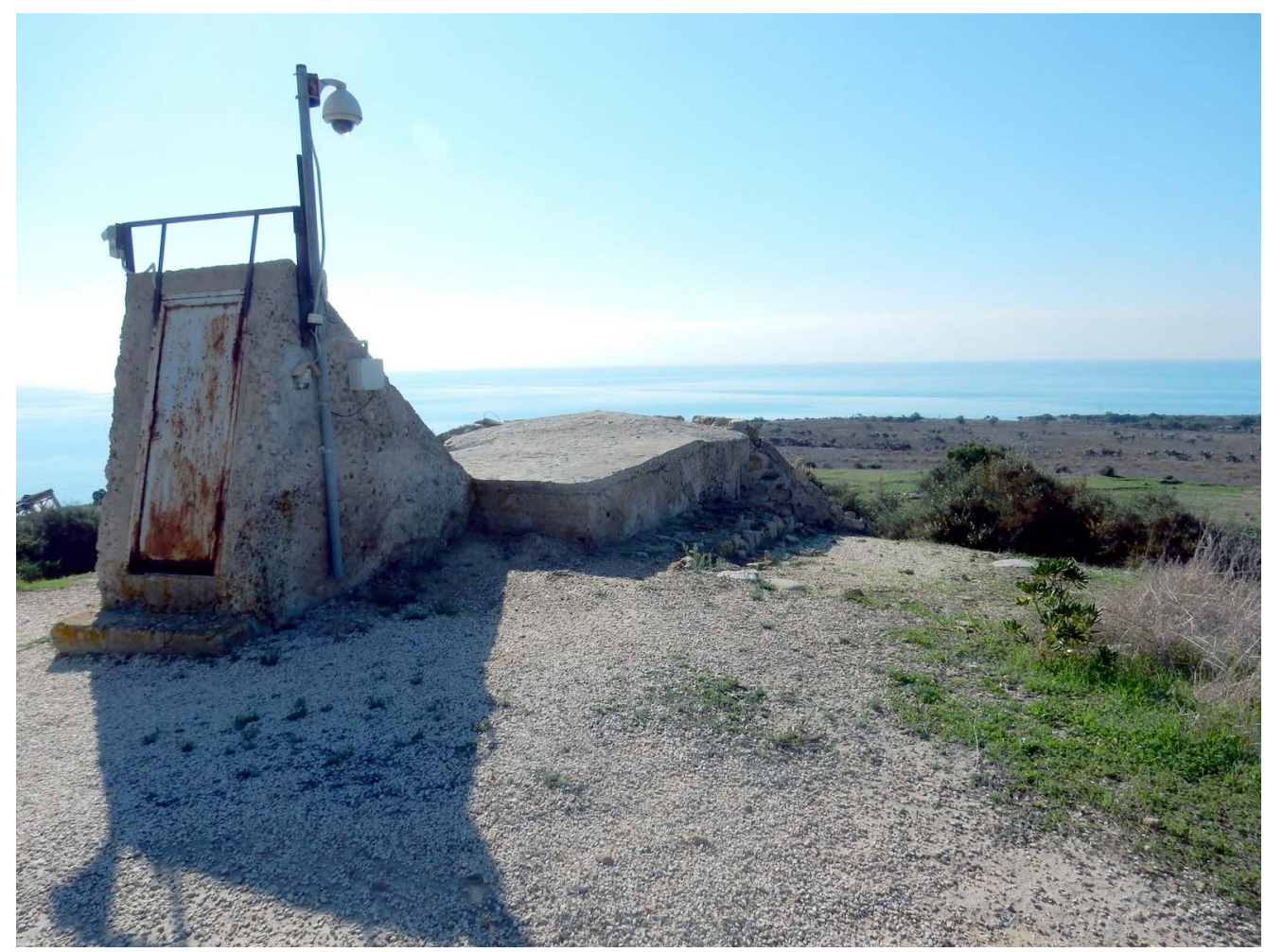

Figure 3. On the left side, inclined entrance portal of the bunker with the original metallic door, a railing and the tele-camera for monitoring the archaeological site, on the right side is visible the top protection of the soldier shelter and the slight arcuate roof of the gun chamber.

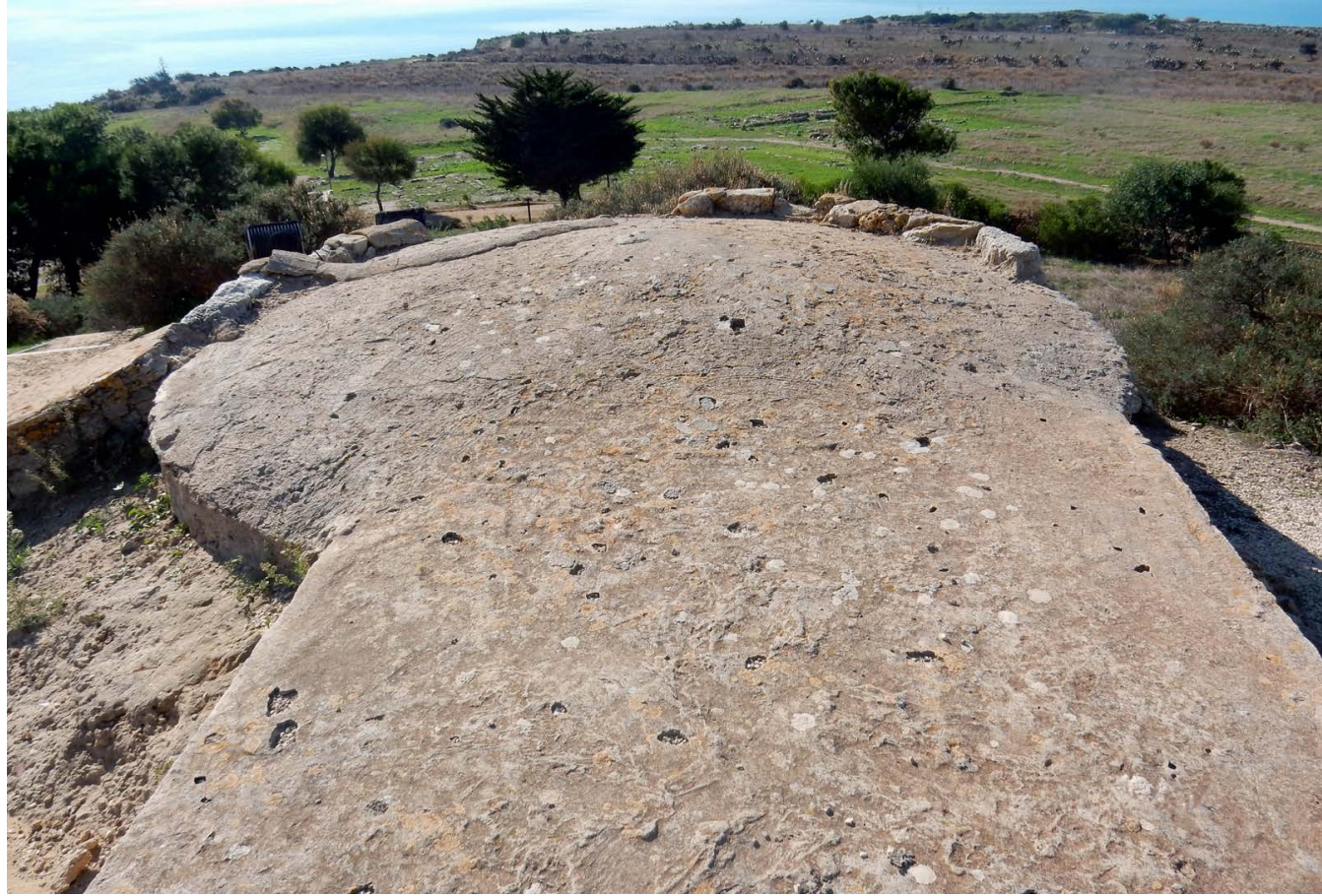

Figure 4. Details of the top protection of the soldier shelter and the gun chamber. 


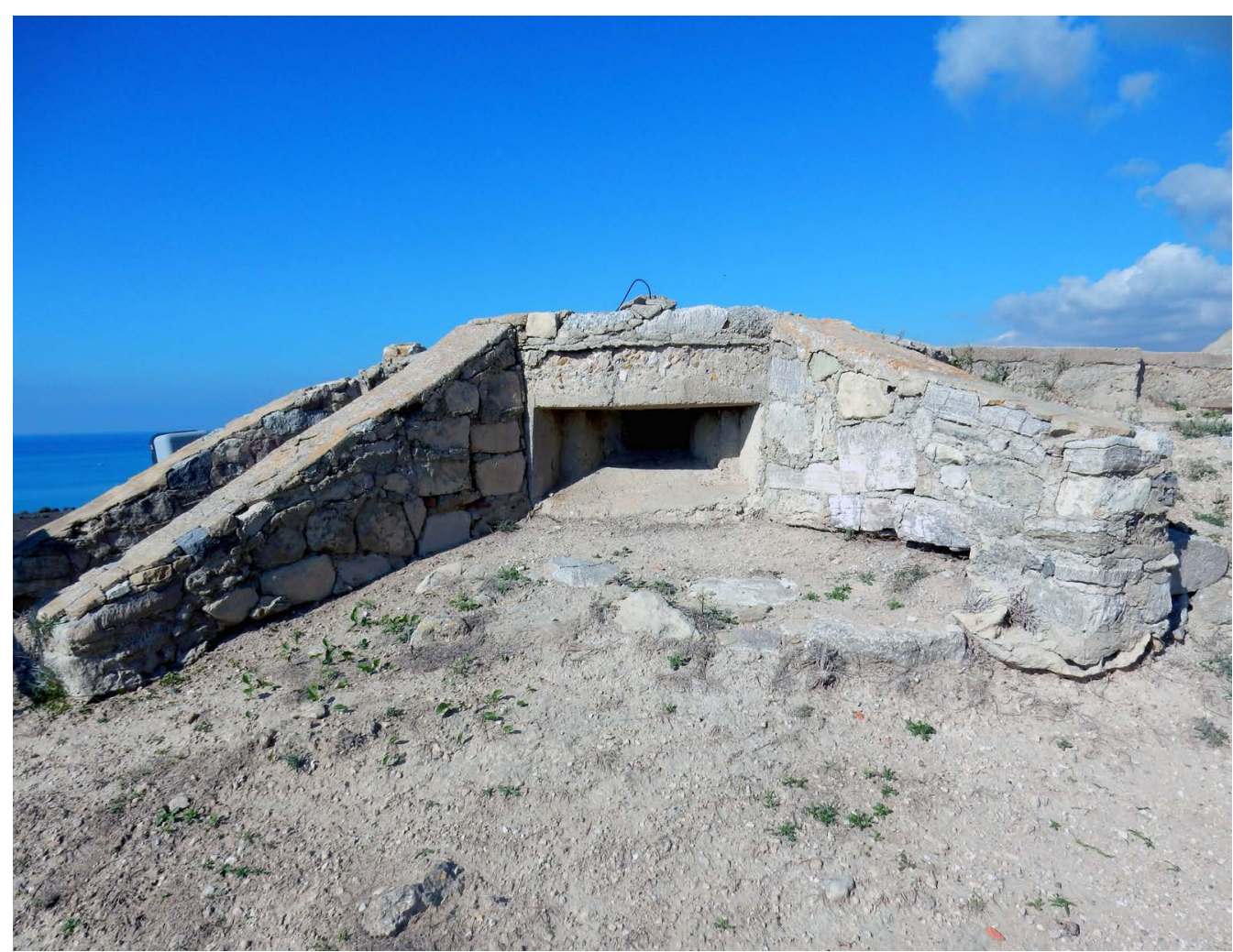

(a)

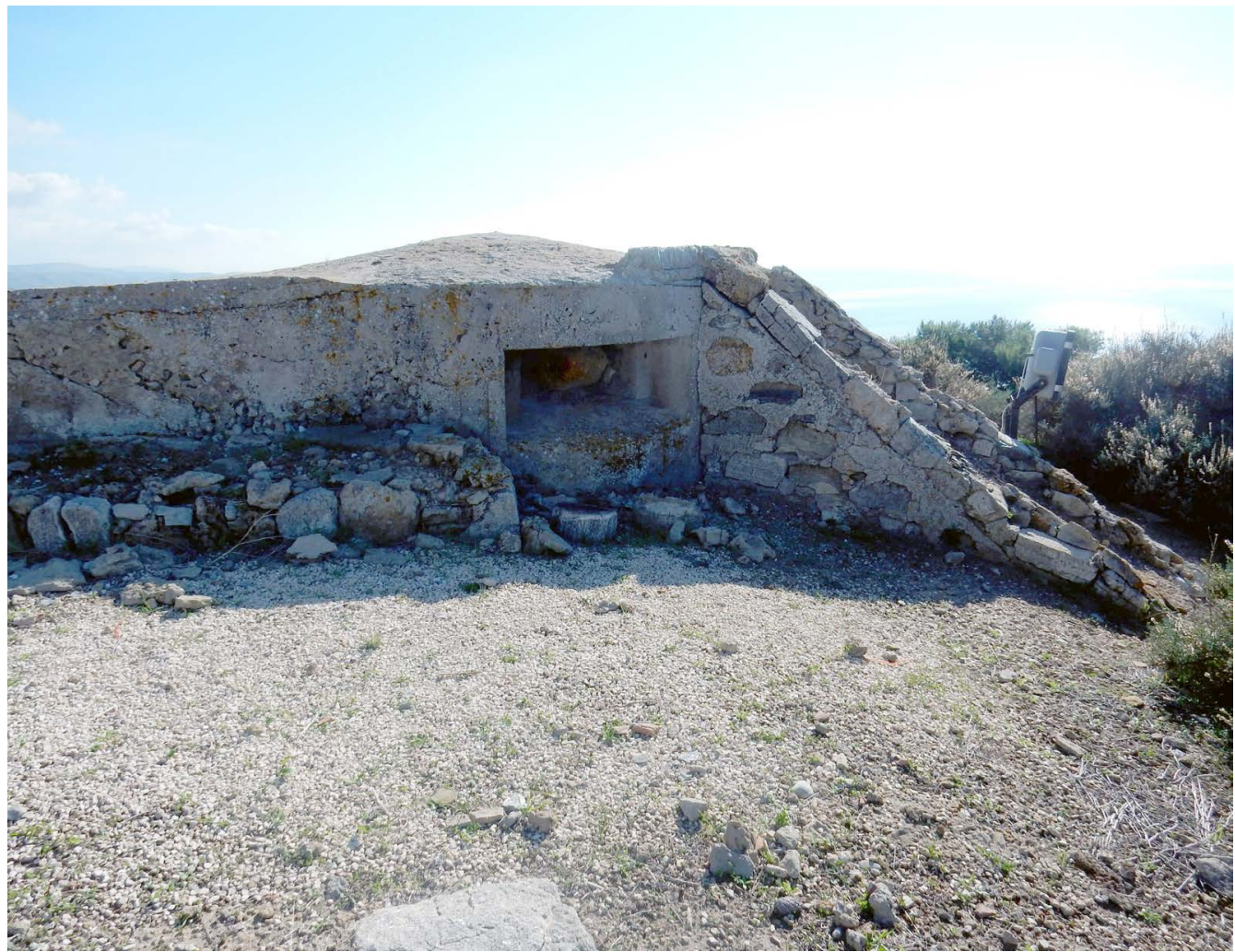

(b)

Figure 5. Rectangular embrasures on the sides of the gun chamber with the radial outgoing stone walls. 


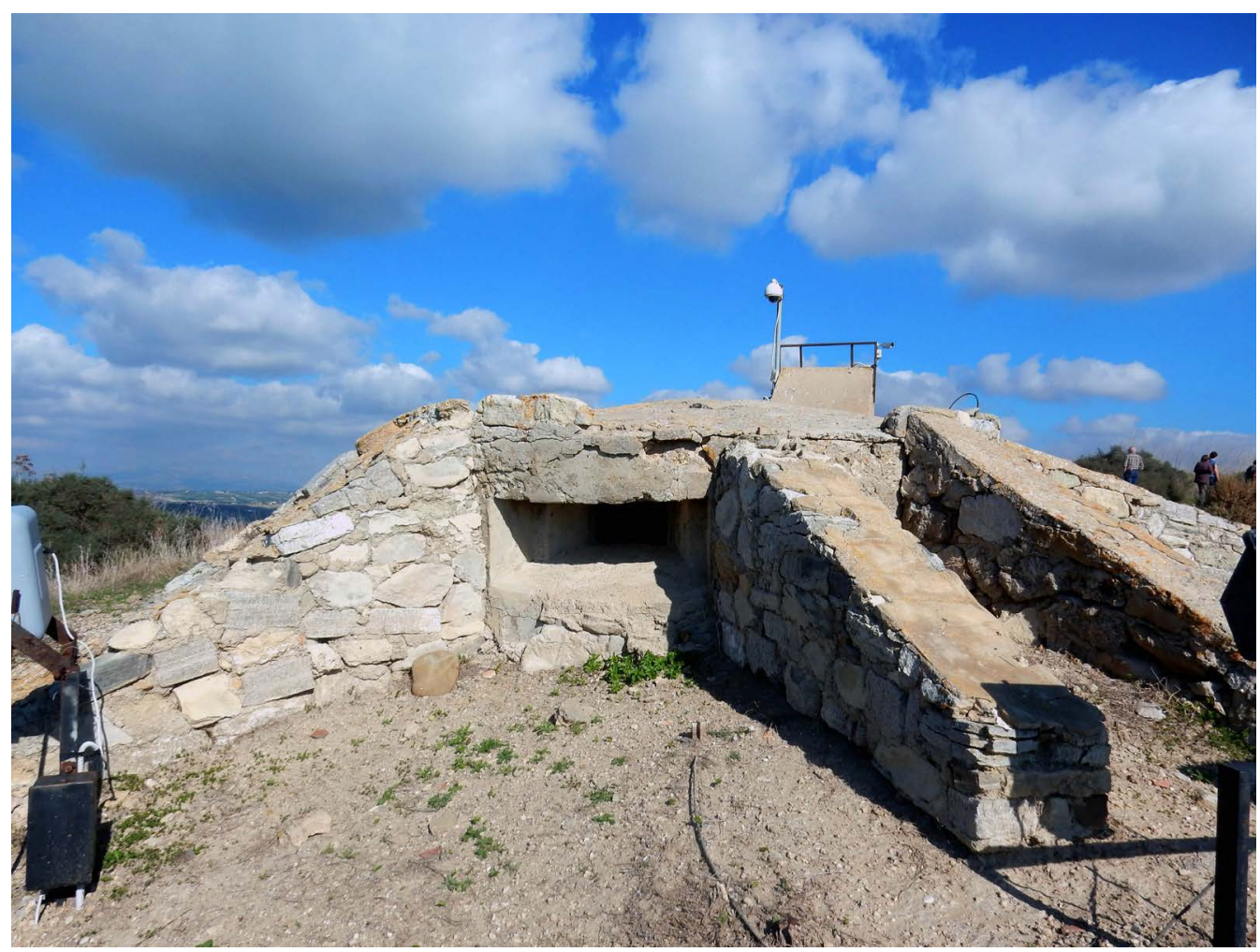

Figure 6. The central embrasure with the radial outgoing stone walls, at the top the inclined entrance portal of the bunker.

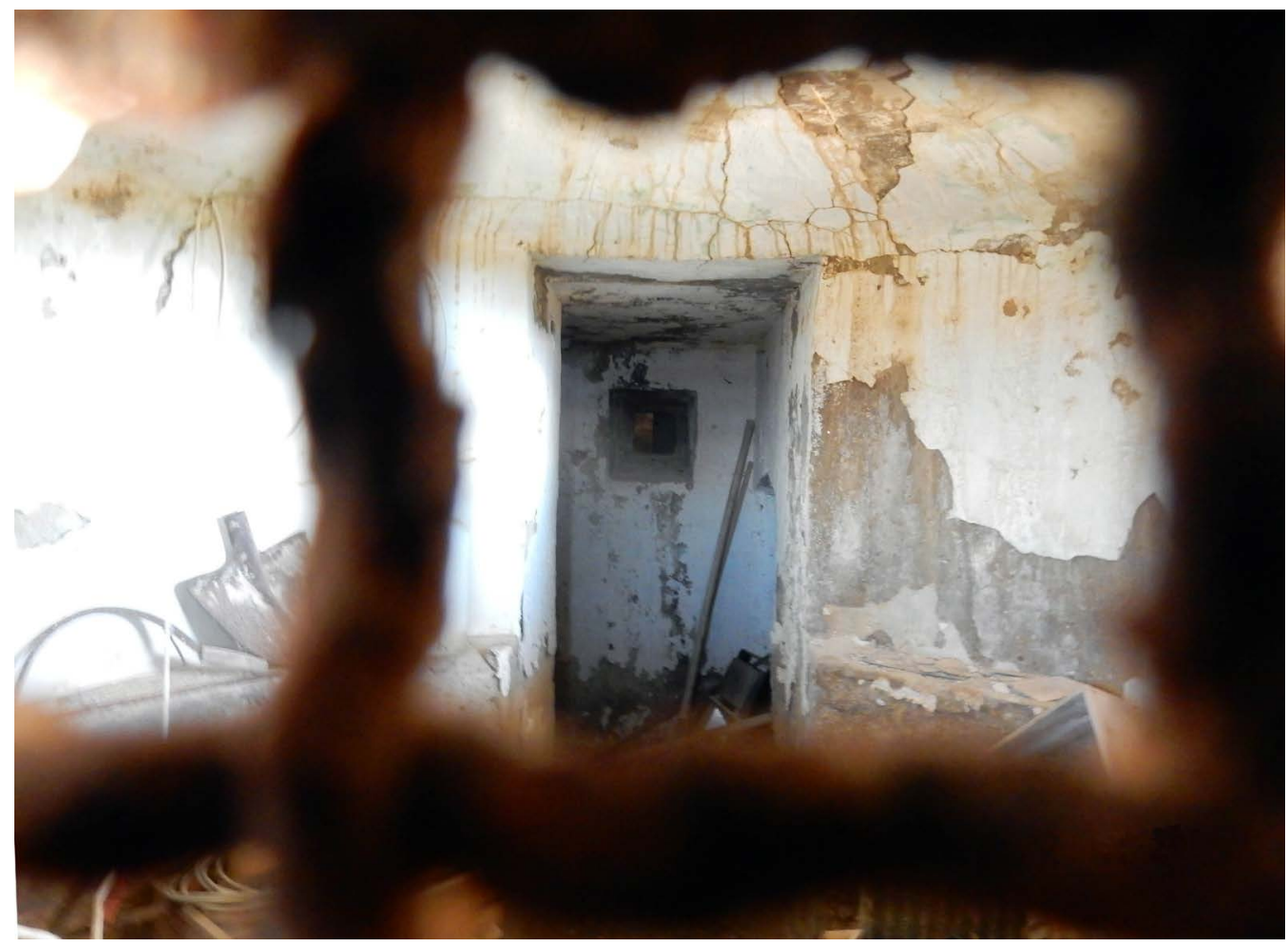

Figure 7. View of the gun chamber, in the middle interior wall with embrasure for the internal defence of the bunker, on the bottom left and right sides portions of the circular shelf. 


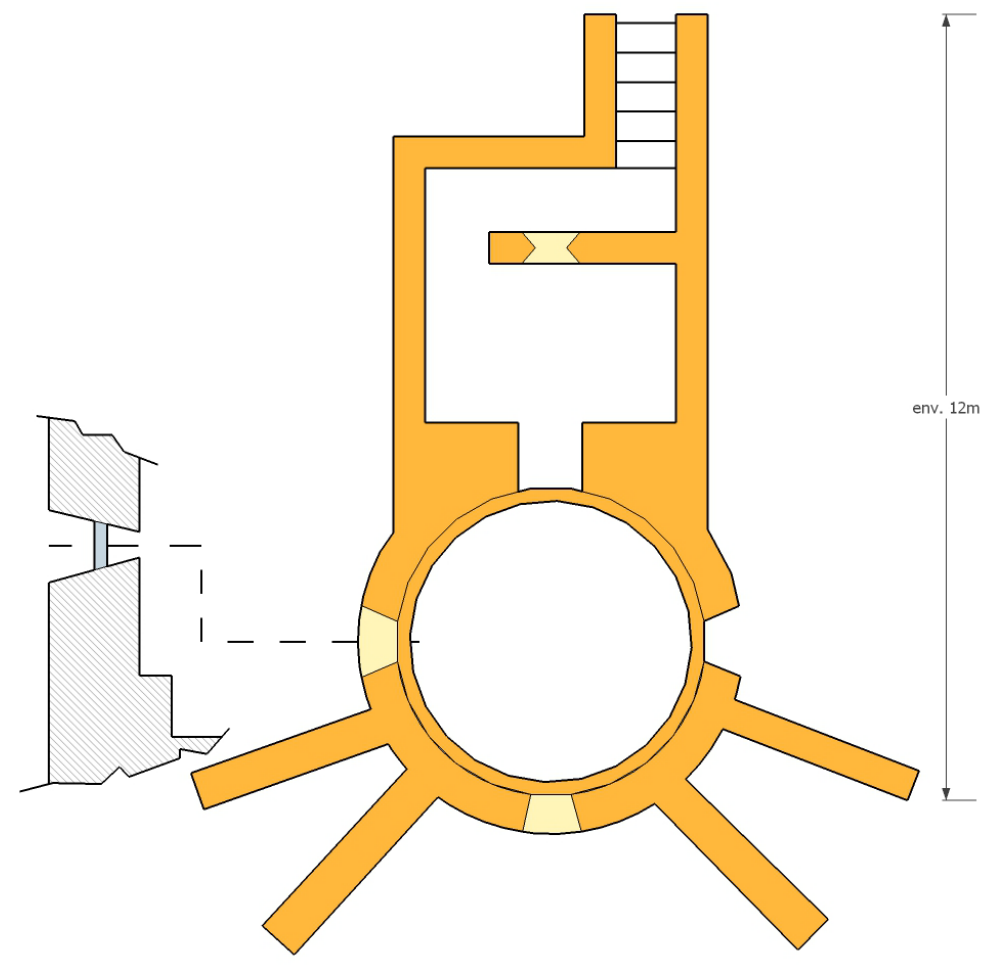

Figure 8. Approximate structure of the bunker-bi-dimensional view.

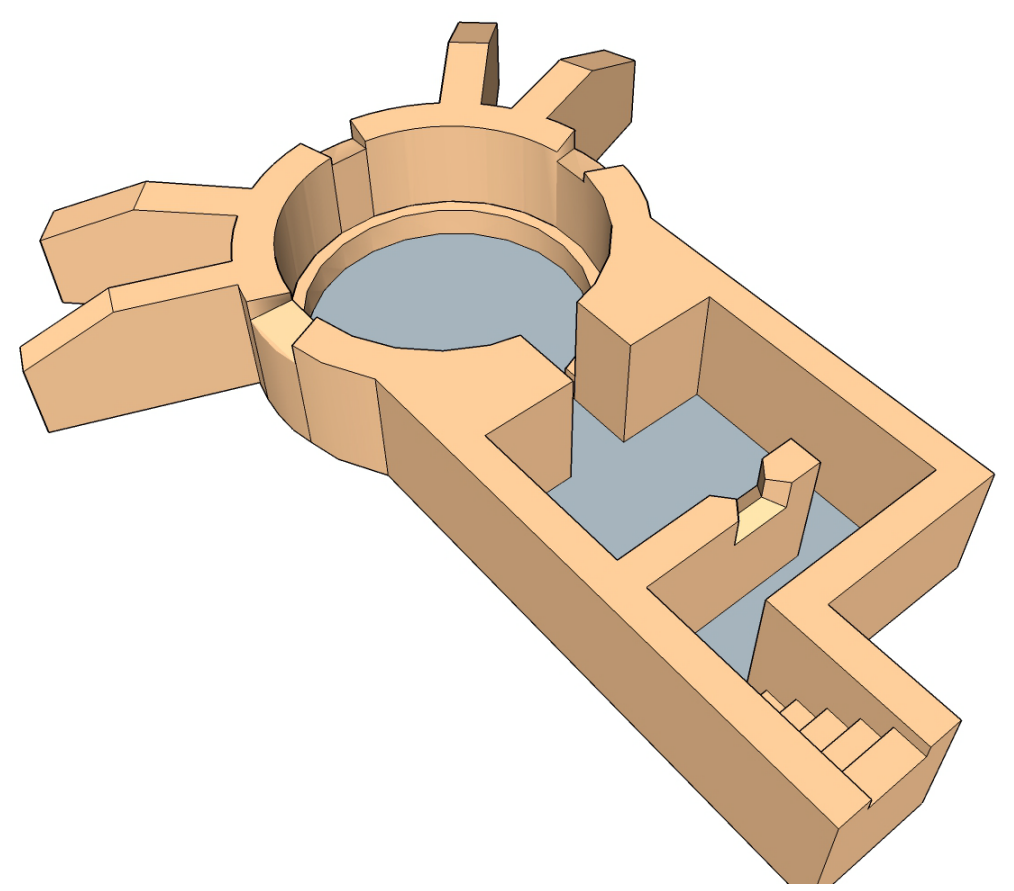

Figure 9. Approximate structure of the bunker-tri-dimensional view.

articles (Collana SISM, 2014), (Tomezzoli, 2012). Furthermore a 30 - $40 \mathrm{~cm}$ wide circular shelf seems to run along the inside wall of the gun chamber. It was probably a support for weapons, ammunition, maps and surveillance tools. It was not possible to ascertain whether the bunker was connected to the coastal defence system by radio or by a telephone line. The bunker appears in a good preservation state without damages caused by 
combats.

\section{Conclusion}

The bunker here described was discovered by chance during a trip in Sicily in the year 2014. Although representing a minor military structure, it is of interest because it allows of improving the knowledge of the WWII Italian bunkers.

\section{Acknowledgements}

I thank Dr. A. Donato member of the Italian Society of Military History (SISM) and Dr. V. Ilari President of SISM for their support in the preparation of the present article and Mr. Y. Marzin for the CAD rendering of the bunker structure in Figure 8 and Figure 9.

\section{References}

Rolf, R. (1968). Atlantic Wall Typology. Amsterdam: Beetsterzwaag.

Grioni, D.

http://www.ilcaleidoscopio.info/page.aspx?page=lepostazionimilitaridelsecondoconflittomondialeinsicilia:unapaginadistor iadariscoprire

Collana SISM.

http://www.societaitalianastoriamilitare.org/COLLANA\%20SISM/2014\%20TOMEZZOLI\%20Fortificazioni\%20di\%20V erona\%201940-45.pdf

Tomezzoli, G. (2012). Militärische Anlagen bei Verona. In DAWA Nachrichten, Ausgabe 59 (pp. 4-27). Köln: Verlag Harry Lippmann. 